Journal of Structural Heart Disease, September 2015, Volume 1, Issue 3: 112-126

DOI: http://dx.doi.org/10.12945/j.jshd.2015.019-14
Received: December 29, 2014 Accepted: January 05, 2015

Published online: September 2015

\title{
Update on New Devices for Transcatheter Aortic Valve Replacement
}

Yigal Abramowitz, MD, Tarun Chakravarty, MD, Hasan Jilaihawi, MD, Raj R. Makkar, MD*

Heart Institute, Cedars-Sinai Medical Center, Los-Angeles, California, USA

\begin{abstract}
Transcatheter aortic valve replacement (TAVR) for severe symptomatic aortic stenosis is the standard of care in inoperable patients and an alternative to surgical aortic valve replacement in high-risk operable patients. Several issues affecting outcomes with implantation of the first-generation TAVR devices remain unresolved, including neurological and vascular complications, atrioventicular conduction abnormalities, and paravalvular aortic regurgitation. New-generation TAVR devices are currently in different stages of clinical development and evaluation. Modifications in the new devices include the ability to reposition the valve before final deployment, features to reduce paravalvular leakage, lower-profile delivery systems, and cerebral protection devices. The purpose of this manuscript is to give an update on the new-generation transcatheter valvular technologies, focusing on the unique features and describing the initial clinical experience for each device.
\end{abstract}

Copyright @ 2015 Science International Corp.

\section{Key Words:}

New devices - Transcatheter aortic valve replacement - Transcatheter aortic valve implantation - TAVR • Transcatheter aortic valve implantation (TAVI)

\section{Introduction}

Transcatheter aortic valve replacement (TAVR) has emerged as a treatment option for inoperable or high-risk surgical patients with severe aortic stenosis (AS) $[1,2]$. Since the first-in-human TAVR procedure

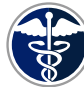

Fax +1 2037853346

E-Mail: jshd@scienceinternational.org

http://structuralheartdisease.org/
(C) 2015 Journal of Structural Heart Disease Published by Science International Corp. ISSN 2326-4004

Accessible online at:

http://structuralheartdisease.org/ performed by Professor Alan Cribier in 2002 [3], more than 100,000 TAVR procedures have been performed worldwide. Considerable experience has been acquired with the two first-generation TAVR devices: the balloon-expandable Edwards SAPIEN/SAPIEN XT (Edwards Lifesciences, Irvine, CA, USA) and the selfexpandable Medtronic CoreValve (Medtronic, Minneapolis, MN, USA). Randomized clinical trials comparing this technology in high risk patients against surgery or medical therapy, as well as multicenter national registries have shown high success rate and increasingly predictable results $[2,4-7]$.

Clinical outcomes of TAVR have improved over the years, mainly as a result of appropriate patient selection, growing operator experience, and major technical refinements. Nonetheless, the rate of complications related to TAVR remains substantial. A recent meta-analysis found the risk of periprocedural stroke following TAVR to be $1.5 \%$ and a 30 -day stroke/ transient ischemic attack (TIA) rate of 3.3\%. Paravalvular aortic regurgitation (PV-AR) after TAVR, including small or trace leaks is quite common (incidence $50-85 \%)$, with the vast majority of cases graded as mild or less [8, 9]. Increasing severity of PV-AR following TAVR have been directly associated with increased mortality $[2,7,9,10]$. Other issues affecting short and long term outcome following TAVR include hemorrhagic and vascular complications, atrioventricular conduction abnormalities, valve malpositioning and coronary obstruction [11]. To overcome these obstacles, and in order to enable the utilization of TAVR for lower risk populations, new-generation TAVR devices

*Corresponding Author:

Raj R. Makkar, MD

Cedars-Sinai Heart Institute

Cedars-Sinai Medical Center

Los Angeles, California, 90048

Tel: +1 310423 3977, Fax: +1 310423 0106, E-Mail: Raj.Makkar@cshs.org 


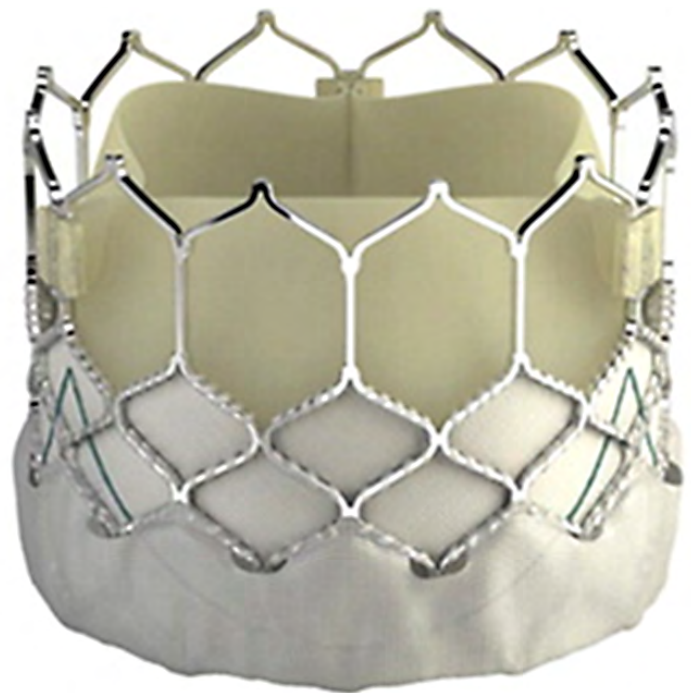

Figure 1: The SAPIEN 3 (S3) valve. A balloon-expandable valve composed of a radiopaque, cobalt chromium frame and a trileaflet bovine pericardial tissue valve. The inflow of the S3 valve is covered by an internal polyethylene terephthalate skirt and an additional outer polyethylene terephthalate cuff to enhance paravalvular sealing.

are currently in early stages of clinical evaluation. Modifications in these new devices include the ability to reposition and recapture the valve before final deployment, features intended to minimize PV-AR, and the introduction of low- profile delivery systems. The present manuscript provides an update on the new-generation transcatheter valvular technologies, focusing on the unique features and describing the initial clinical experience for each device.

\section{Edwards Lifesciences SAPIEN 3}

The SAPIEN 3 (S3) valve (Edwards Lifesciences, Irvine, CA, USA) is a new balloon-expandable valve that can be implanted using the transfemoral, transsubclavian, transapical, or transaortic approaches. It incorporates features intended to reduce vascular complications, increase paravalvular sealing, and enhance ease of positioning [12]. This device is composed of a radiopaque, cobalt chromium frame and a trileaflet bovine pericardial tissue valve (Figures 1, 2 and Movie 1). It incorporates a stent and leaflet design that allows for crimping to a reduced profile as compared with the predicate SAPIEN and SAPIEN $\mathrm{XT}$ devices. The inflow of the S3 valve is covered by an internal polyethylene terephthalate skirt similar

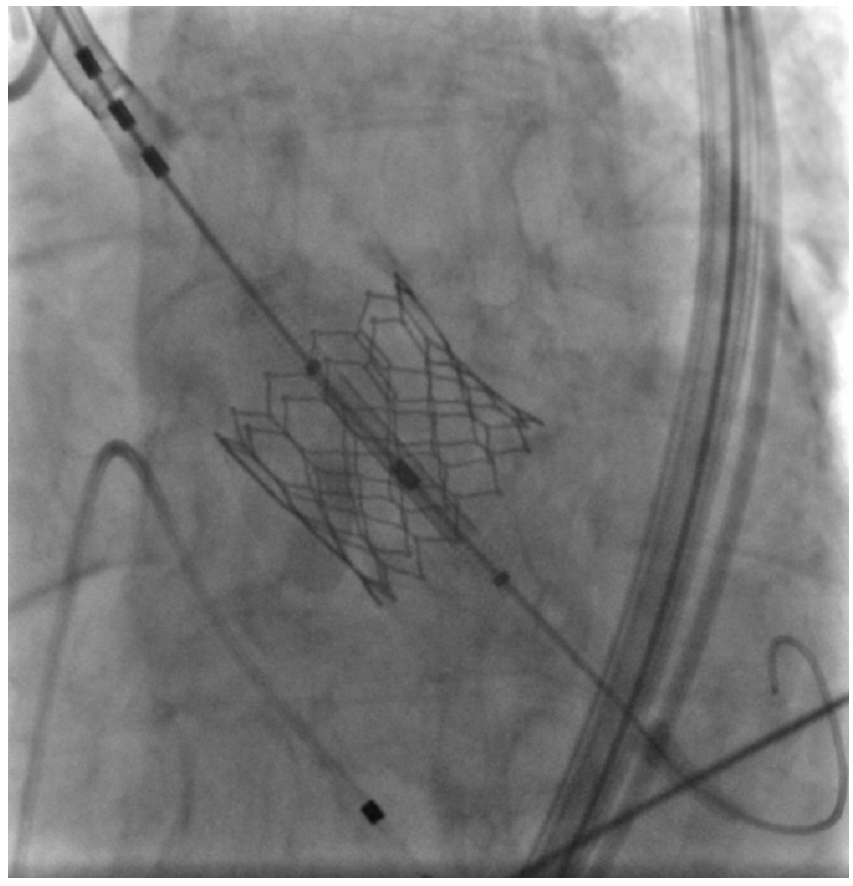

Figure 2: Angiography of SAPIEN 3 valve implantation.

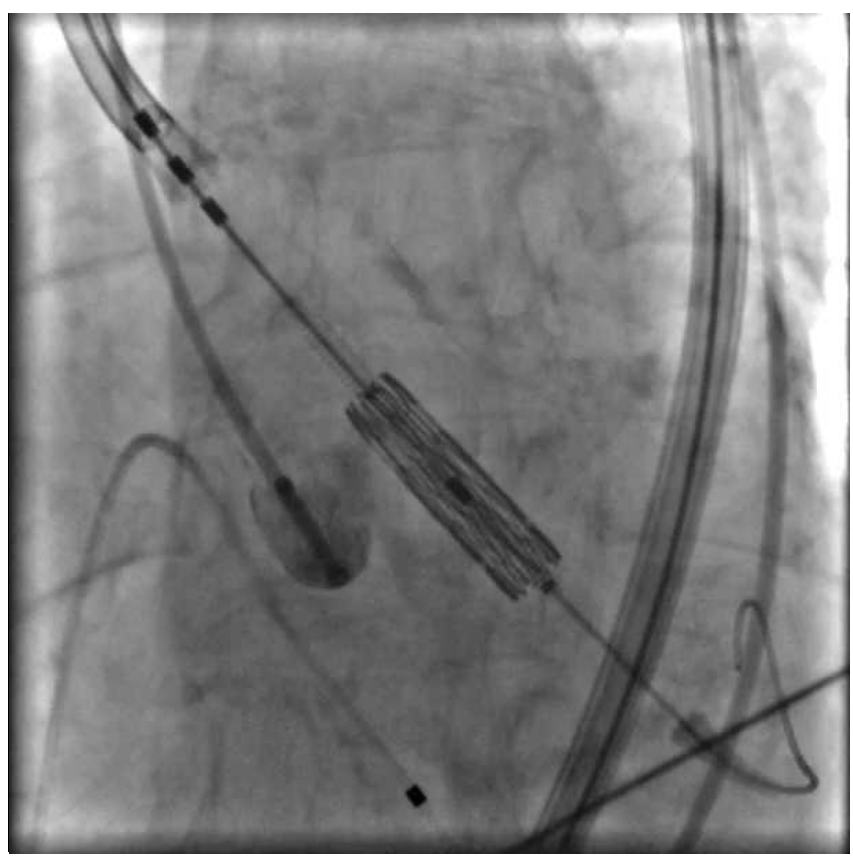

Video 1: Angiography of SAPIEN 3 valve deployment.

to the earlier SAPIEN XT device. However, the S3 incorporates an additional outer polyethylene terephthalate cuff to enhance paravalvular sealing thus reducing PV-AR. This sealing cuff has no filling and 
functions like a parachute by bulging outward [13]. The Edwards Commander transfemoral delivery system (Edwards Lifesciences, Irvine, CA, USA) has lower profile and higher flexibility compared to the currently used NovaFlex system (Edwards Lifesciences, Irvine, CA, USA). It contains a fine adjustment wheel that permits a precise positioning of the crimped valve in the aortic annulus without unnecessary pushing or pulling. A central radiopaque marker in the balloon also assists in valve positioning. The system uses a 14-F expandable eSheath (Edwards Lifesciences, Irvine, CA, USA), that intend to reduce the potential for arterial injury during introduction but can transiently expand to accommodate passage of the compressed valve and then return to its lower profile diameter.

Recently, the 30-day outcomes of 150 patients that underwent S3 valve implantation in Europe and Canada were published [14]. A transfemoral approach was chosen in $64.0 \%$ and transapical/direct aortic in the remainder. At 30 days, PV-AR was none to mild in $96.4 \%$ and moderate in $3.5 \%$. No patient had severe regurgitation. Transfemoral implantation was associated with low 30 -day mortality $(2.1 \%)$ and no disabling stroke. Alternative access was associated with higher rates of 30 -day mortality $(11.6 \%)$ and stroke (5.6\%). This device is available in 20-, 23-, 26-, and $29-\mathrm{mm}$ sizes and is expected to facilitate fully percutaneous implantation in a broader range of patients with the potential for more accurate positioning and less PV-AR. The initial 30-day outcomes of the PARTNER II S3 Trial $(n=1,659)$ have demonstrated 30day mortality rate of $2.2 \%$ for the overall high-risk cohort and $1.1 \%$ for the intermediate-risk cohort. Moderate or higher PV-AR at 30-days was present in $2.9 \%$ of the high-risk patients and $4.2 \%$ of the intermediate-risk patients [15]. Since June 2015, Sapien 3 has a U.S. Food and Drug Administration (FDA) approval.

Currently ongoing trials with SAPIEN 3 valve are the PARTNER II trial (Placement of aortic transcatheter valves; ClinicalTrials.gov Identifier: NCT01314313) and the safety and performance study of the Edwards SAPIEN 3 transcatheter heart valve trial (NCT01808287).

\section{Medtronic CoreValve Evolute / Evolute R}

The Evolute (Medtronic, Minneapolis, MN, USA) $23 \mathrm{~mm}$ valve was the first next-generation CoreValve

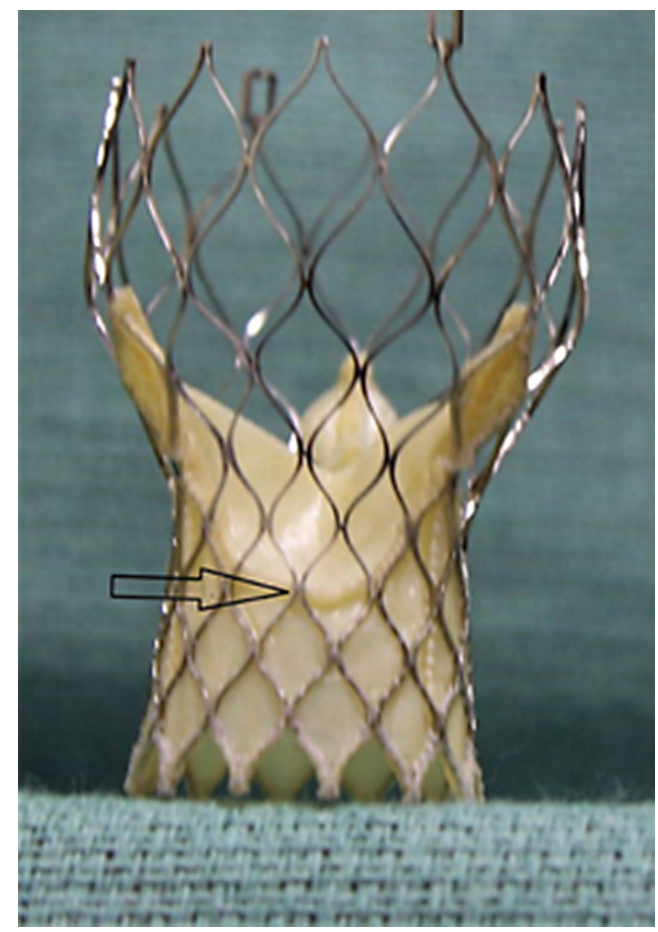

Figure 3: The Evolute valve. A self-expandable valve composed of radiopaque nitinol support frame, supra-annular trileaflet porcine pericardial leaflets, and porcine pericardium fabric skirt. The arrow corresponds to the nadir of the pericardial leaflets.

device (Figure 3). It is indicated for small (18-20 mm) aortic annuli and designed to be fully repositionable, resheathable and recapturable [16]. It has a Conformité Européenne (CE) mark for valve-in-valve implantations since 2013 and was previously described for this indication in case reports $[17,18]$.

The newly designed CoreValve Evolute $\mathrm{R}$ (Medtronic, Minneapolis, MN, USA) is a low-profile system that retains many of the characteristics of its predecessors: radiopaque self-expanding nitinol support frame, supra-annular trileaflet porcine pericardial leaflets, and porcine pericardium fabric skirt [19]. The cell geometry and frame of this valve have been redesigned to optimize frame interaction with the native anatomy, to improve conformability to the aortic annulus and reduce PV-AR. The inflow has more consistent radial force across the sizing spectrum, and the outflow has been shortened and reshaped to provide improved alignment between valve housing and the native sinus. The valve leaflets are routinely treated with alpha-amino oleic acid to impede calcium deposition. The new EnVeo R deliv- 


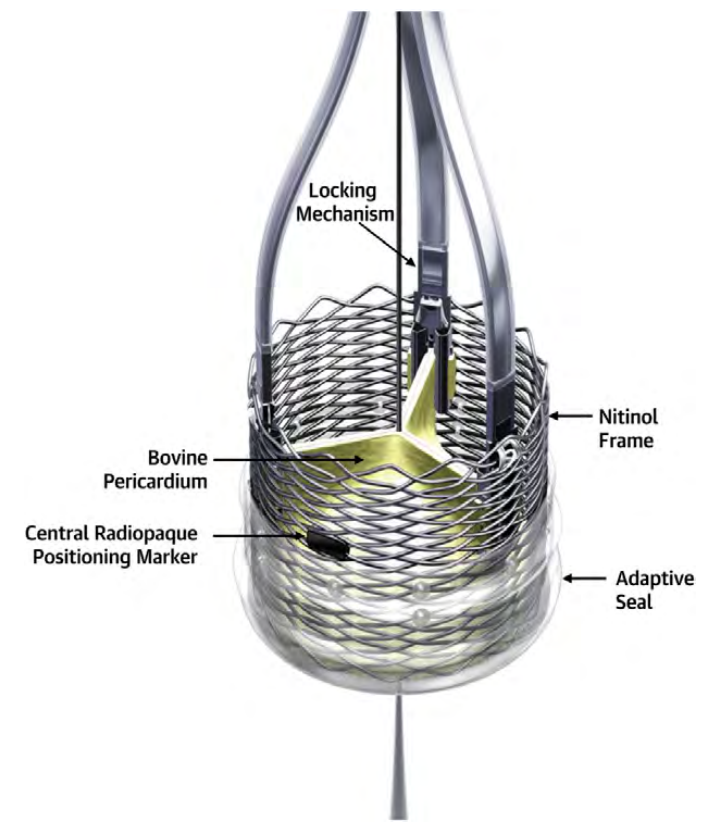

Figure 4: The Lotus Valve System. The bioprosthetic aortic valve implant comprises three bovine pericardial leaflets supported on a braided nitinol frame, and an outer adaptive seal designed to minimize PV-AR.

ery catheter (Medtronic, Minneapolis, MN, USA) features a complete redesign of the AccuTrak system (Medtronic, Minneapolis, MN, USA) that is currently employed for CoreValve implantation. The EnVeo $\mathrm{R}$ catheter with InLine sheath (Medtronic, Minneapolis, MN, USA) is a $14 \mathrm{Fr}$-equivalent system that can deliver the transcatheter heart valve without the requirement for a separate introducer sheath. The modified valve capsule allows the valve to be fully recaptured and repositioned during deployment. The valve is available in 23, 26 and $29 \mathrm{~mm}$ sizes. A report of the initial results of implantation of this device in 60 patients revealed no case of mortality at 30 -days and $3.4 \%$ of moderate or higher PV-AR [20]. As of June 2015 Evolut R has a U.S. FDA approval.

Currently ongoing trials with Evolute $\mathrm{R}$ valve are the Medtronic CoreValve Evolute R CE mark clinical study (ClinicalTrials.gov Identifier: NCT01876420) and the Medtronic CoreValve Evolute R U.S. clinical study (NCT02207569).

\section{Boston Scientific Lotus}

The Lotus Valve System (Boston Scientific, Natick, MA, USA) comprises a bioprosthetic aortic valve im- plant and a catheter-based delivery system for introduction and delivery of the valve implant [21]. The bioprosthetic aortic valve implant comprises three bovine pericardial leaflets supported on a braided nitinol frame (Figure 4). An outer adaptive seal is designed to minimize PV-AR. Currently, the valve is available in 23- and 27-mm sizes; an additional valve size of $25 \mathrm{~mm}$ is anticipated. The transfemoral delivery system is $18 \mathrm{Fr}$ compatible. The delivery handle incorporates a simple, ergonomic design that enables a controlled, predictable, and accurate deployment. If the initial deployment is suboptimal, the device can be subtly advanced or retracted as needed or even completely retracted into the delivery sheath at any time prior to the final release. The valve functions early in deployment, providing hemodynamic stability for the patient and enabling the operator to complete the delivery process in a controlled and considered fashion.

The multicenter REPRISE II study has been recently published [22]. It examined transfemoral implantation of 23- or 27-mm Lotus valve in 120 patients with severe AS. The valve was successfully implanted in all patients, with no cases of valve embolization or additional valve implantation. All repositioning $(n=26)$ and retrieval $(n=6)$ attempts were successful; 34 patients $(28.6 \%)$ received a permanent pacemaker. The Mean gradient improved from $46.4 \pm 15 \mathrm{~mm} \mathrm{Hg}$ to $11.5 \pm 5.2 \mathrm{~mm} \mathrm{Hg}$. At 30 days, the mortality rate was $4.2 \%$, and the rate of disabling stroke was $1.7 \%$; one patient had moderate PV-AR, whereas none had severe PV-AR. CE mark approval for Lotus valve system was obtained in 2013.

Four clinical trials evaluating efficacy and safety of Lotus valve implantation are currently ongoing (ClinicalTrials.gov Identifier: NCT02202434, NCT02031302, NCT01627691, NCT01383720).

\section{Direct Flow Medical Valve}

The Direct Flow Medical aortic valve (Direct Flow Medical, Santa Rosa, CA, USA) is a nonmetallic percutaneous valve with an inflatable ring cuff frame designed to encircle and capture the native valve annulus, thereby ensuring anchoring of the bioprosthesis and minimizing potential PV-AR, dislodgement or migration [23] (Figure 5). The tricuspid bovine pericardial valve is attached to a polyester 


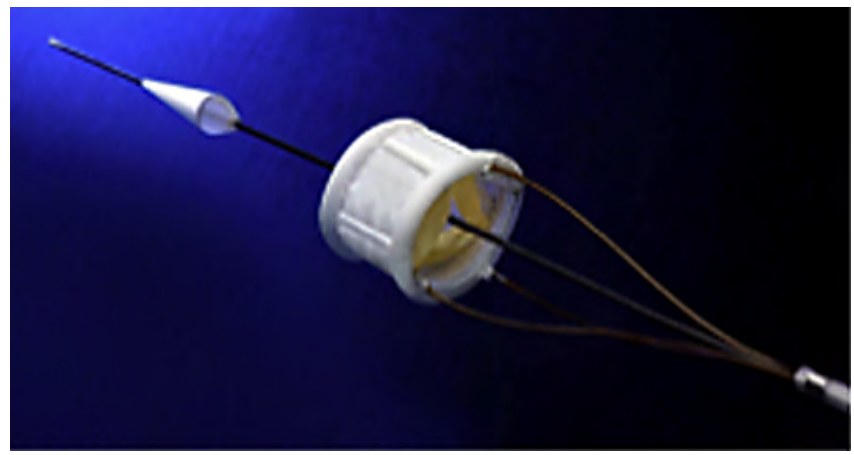

Figure 5: The Direct Flow Medical aortic valve. A tricuspid bovine pericardial valve is attached to a polyester fabric cuff which conforms to the native aortic annulus.

fabric cuff which conforms to the native aortic annulus. An upper (aortic) and lower (ventricular) ring balloon interconnected by a tubular bridging system can be inflated independently through two of the three position-fill lumens. The valve is available in 25- and 27-mm sizes. It is designed to be fully repositionable and retrievable prior to final deployment through the introducer. The $18 \mathrm{Fr}$ delivery system contains three position-fill lumens which are attached to the bioprosthesis. Two of these position-fill lumens are used to inflate and deflate the ring balloons and all three are used to position the bioprosthesis.

The results of a prospective multicenter evaluation of the direct flow medical transcatheter aortic valve have been recently published [24]. One-hundred patients with severe AS underwent transfemoral implantations. Device success was $93 \%$, all-cause mortality at 30 days was $1 \%$, and major stroke rate was $4 \%$. The post-implantation echocardiography results demonstrated mild or no aortic regurgitation (AR) in $99 \%$ with a mean gradient of $12.6 \pm 7.1 \mathrm{~mm} \mathrm{Hg}$ and effective orifice area of $1.50 \pm 0.56 \mathrm{~cm}^{2}$. The direct flow medical valve has received a CE mark at 2013.

Three clinical trials evaluating efficacy and safety of Direct Flow Medical aortic valve implantation are currently ongoing (NCT01845285, NCT02163850, and NCT01932099).

\section{St. Jude Medical Portico}

The trileaflet self-expanding Portico valve (St. Jude Medical, Minneapolis, MN, USA) consists of a nitinol frame, bovine pericardial leaflets processed with the

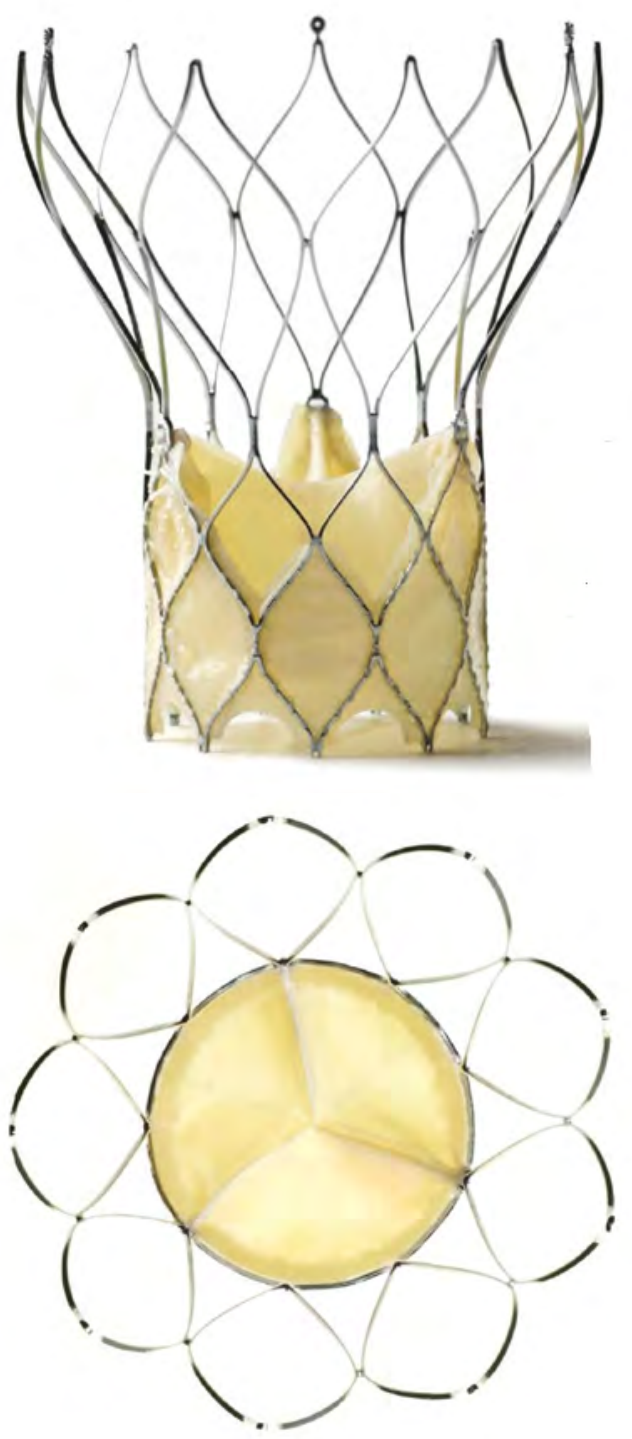

Figure 6: The Portico valve. A self-expandable valve composed of a nitinol frame, bovine pericardial trileaflets processed with the Linx anti-calcification technology and a porcine pericardial sealing cuff.

Linx anticalcification technology and a porcine pericardial sealing cuff $[25,26]$ (Figures 6 and 7 ). The outflow portion of the stent frame incorporates three retention tabs, which secure the crimped valve to the delivery system [26]. The transfemoral delivery catheter consists of a soft tapered nose cone, an 18 Fr capsule that contains the compressed valve, and a $12 \mathrm{Fr}$ shaft. The system is designed to deliver the valve gradually, deploying it to the point of functionality while allowing for controlled recapture, followed by 


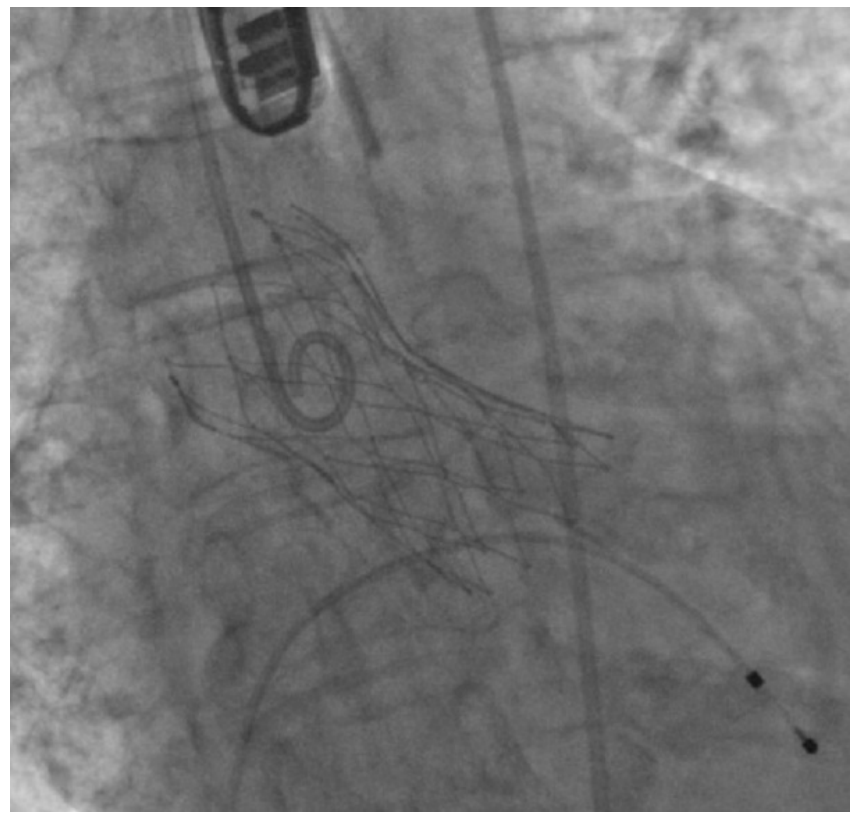

Figure 7: Angiography of a Portico valve.

either by repositioning and redeployment or by removal. Portico transaortic and subclavian delivery systems will also be available with designs similar to the transfemoral system. The 24 Fr delivery system used for transapical approach is composed of a tapered nose cone, a capsule containing the compressed valve and similarly allows repositioning of the valve if needed [27]. The Portico valve is sized according to the nominal external stent diameter at the valvular level. Currently, 23- and 25-mm devices are available for commercial use in Europe, and 27- and 29-mm devices are being evaluated in clinical trials.

First-in-human experience with Portico device included a $23-\mathrm{mm}$ device implanted in 10 patients with severe AS via transfemoral approach [26]. At 30-day follow-up, echocardiographic mean transaortic gradient was reduced from $44.9 \pm 16.7 \mathrm{~mm} \mathrm{Hg}$ to $10.9 \pm 3.8 \mathrm{~mm} \mathrm{Hg}(p<0.001)$, and aortic valve area (AVA) increased from $0.6 \pm 0.1 \mathrm{~cm}^{2}$ to $1.3 \pm 0.2 \mathrm{~cm}^{2}(p<$ $0.001)$. PV-AR was mild or less in 9 patients and moderate in 1 patient. There were no major strokes, major vascular complications, major bleeds, or deaths. No patient required pacemaker implantation. A case report of transapical Portico implantation has also been described [27].

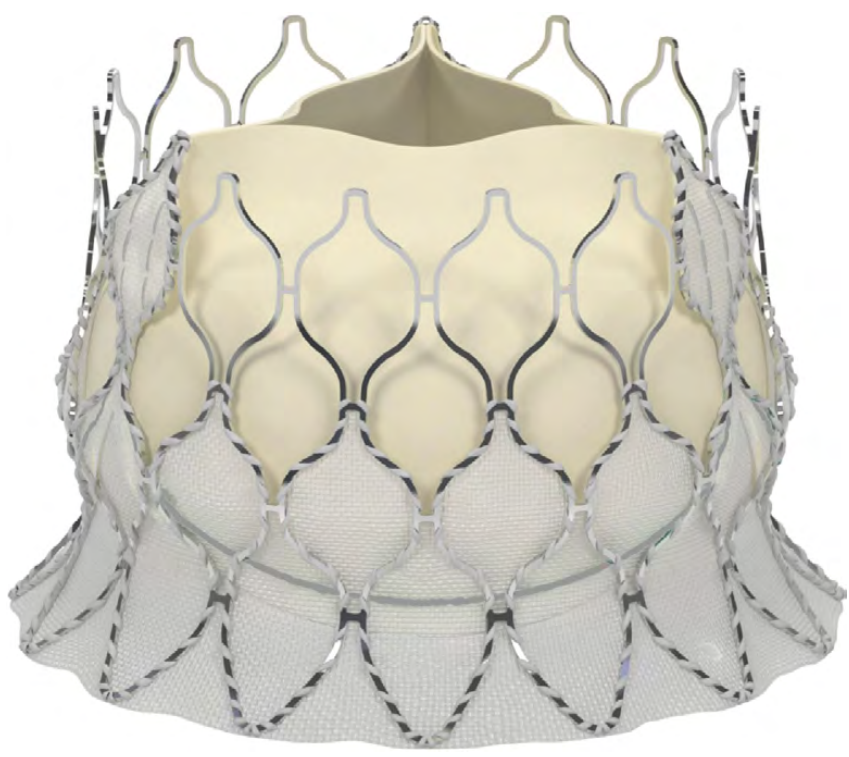

Figure 8: The CENTERA valve. A self-expandable ultra-low-profile valve that consists of three bovine pericardial tissue leaflets attached to a nitinol frame with a polyethylene terephthalate skirt intended to minimize PV-AR.

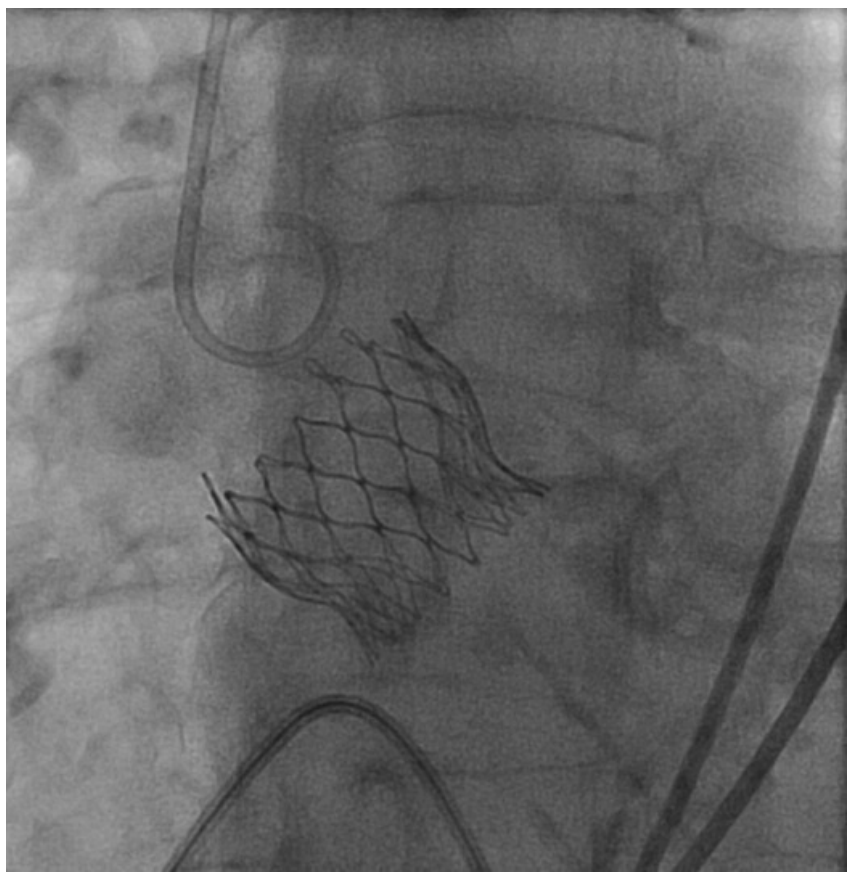

Figure 9: Angiography of a Centera valve.

Five clinical trials evaluating efficacy and safety of Portico valve implantation are currently ongoing (ClinicalTrials.gov Identifier: NCT02000115, NCT01802788, NCT01742598, NCT01493284, and NCT02088021). 


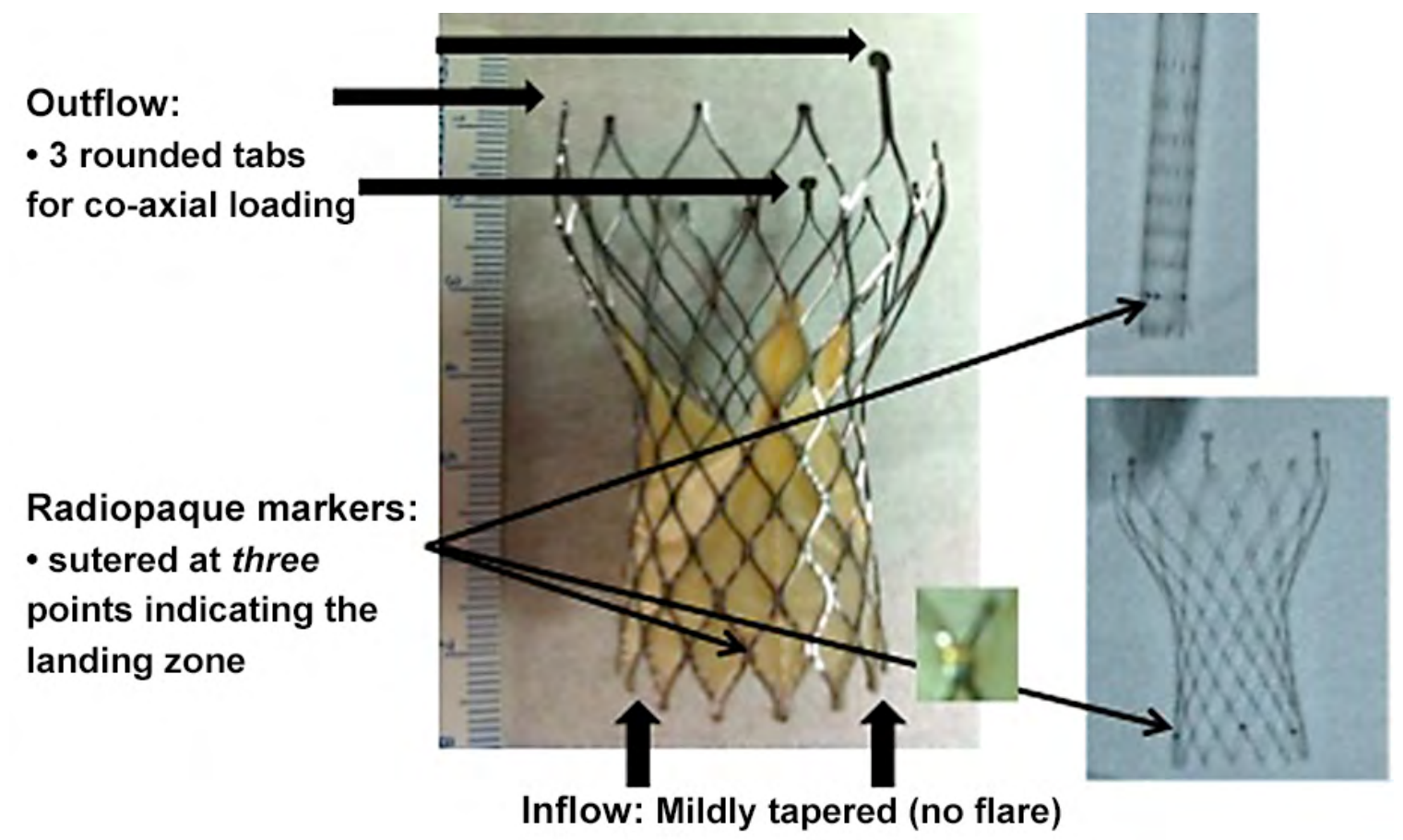

Figure 10: The Venus A valve. A self-expandable valve composed of a nitinol stent frame carrying a trileaflet bioprosthetic valve made of porcine pericardial leaflets.

\section{Edwards Lifesciences Centera}

The self-expandable CENTERA valve (Edwards Lifesciences, Irvine, CA, USA) is an ultra-low-profile valve that consists of three treated bovine pericardial tissue leaflets attached to a nitinol frame with a polyethylene terephthalate skirt intended to minimize PV-AR [28] (Figures 8 and 9). Currently, the valve is available in 23- and 26-mm sizes; an additional valve size of $29 \mathrm{~mm}$ is anticipated. The stent frame does not have a flared distal section that extends into the ascending aorta and therefore is shorter than that of other self-expandable valves. This facilitates self-centering and seating of the valve within the annulus, and it may also help to improve paravalvular sealing with minimal protrusion of the valve frame into the left ventricle. The delivery system consists of a delivery catheter and a detachable, battery-powered motorized handle, which can be delivered by the transfemoral or subclavian approaches. The capability to re-sheath and reposition in situ prior to complete valve deployment is an expected feature and may reduce the risk of valve malposition or embolization. The delivery system is compatible with a $14 \mathrm{Fr}$ eSheath. The dynamic expansion mechanism of the eSheath allows for transient sheath expansion during valve delivery. Immediately after the valve passes through the sheath, the sheath return to a lowprofile diameter thus reducing the time the access vessel is expanded, and minimizing the risk of vascular trauma.

The CENTERA valve was implanted in 15 patients with symptomatic severe AS via transfemoral $(n=11)$ or transaxillary $(n=4)$ approaches [29]. All 15 implantations were successful. Post-procedurally, AVA increased from $0.7 \pm 0.1 \mathrm{~cm}^{2}$ to $1.6 \pm 0.4 \mathrm{~cm}^{2}(p<0.01)$ and mean trans-aortic gradient decreased from $36.3 \pm 14.2 \mathrm{mmHg}$ to $10.6 \pm 5.4 \mathrm{mmHg}(\mathrm{p}<0.001)$. PV-AR at 30-day follow-up was none or trivial in $23 \%$, mild in $69 \%$ and moderate in $8 \%$ of the patients. Survival was $87 \%$ at 30 days and $80 \%$ at 1 year, and four patients $(27 \%)$ received a new permanent pacemaker.

The safety and performance study of the Edwards CENTERA self-expanding transcatheter heart valve trial is currently ongoing (ClinicalTrials.gov Identifier: NCT01808274). 


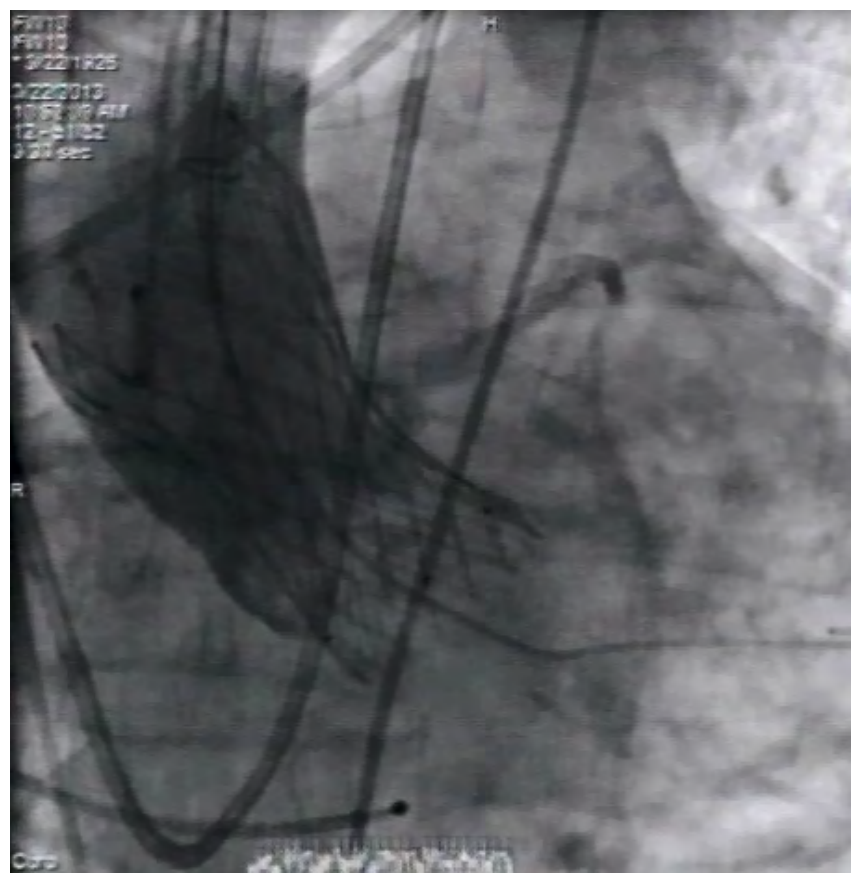

Figure 11: Aortography with contrast injection of a patient with Venus A valve following TAVR.

\section{Venus A Valve}

The Venus A Valve (Venus Medtech, Hangzou Inc., Shanghai, China) is a self-expanding nitinol stent frame carrying a trileaflet bioprosthetic valve made of porcine pericardial leaflets (Figures 10 and 11). The delivery system is $18 \mathrm{Fr}$ and can be delivered sheathless by the transfemoral and transaxillary/transsubclavian approach and with a sheath for the transaortic approach [30]. The radial force of expansion for the inflow was increased early in the study, enabling a more consistent device expansion in the presence of extreme aortic valve calcification, which had been frequently observed in the treated population.

Moreover, midway in the first-in-man study, the inclusion criteria were extended to bicuspid aortic valve disease, given the frequency of cases encountered in China. Patients are treated under local anesthesia for the transfemoral and transaxillary approach and under general anesthesia for the transaortic approach. The first in-man Venus A-Valve trial is currently ongoing (ClinicalTrials.gov Identifier: NCT01683474). Recently, the initial results of Venus A valve implantation in 101 patients have been presented [30]. At 30-days, all-cause mortality was $2 \%$ and moderate-severe PVAR rate was $6 \%$.

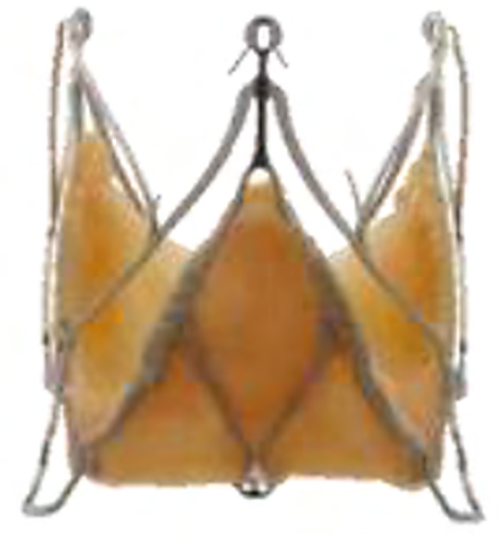

Figure 12: The JenaValve. A self-expandable composed of a full porcine root valve mounted on a low-profile nitinol stent. A unique clip fixation mechanism provides anchoring to the native leaflets.

\section{JenaValve}

The self-expandable JenaValve (JenaValveTechnology $\mathrm{GmbH}$, Munich, Germany) consists of a full porcine root valve mounted on a low-profile nitinol stent [31] (Figure 12). In contrast to devices expanding within the aortic annulus, it relies on an active clip fixation of the native aortic valve leaflets, thereby eliminating great radial forces on cardiac and aortic structures. This allows for a short stent design that prevents coronary compromise by the native leaflets or stent struts, and that does not interfere with future coronary intervention. The unique clip fixation mechanism can provide secure anchoring to the native leaflets even in the absence of calcification and therefore may be utilized successfully for the treatment of non-calcified pure aortic regurgitation (AR) [32]. The feature of anatomically aligned positioning eliminates the need for rapid pacing during implantation. The device is delivered via transapical approach using a sheathless 32 Fr delivery catheter that is utilized for three-step deployment procedure. The valve is available in three different sizes $(23 \mathrm{~mm}, 25 \mathrm{~mm}$, and $27 \mathrm{~mm}$ ) for implantation in native aortic annuli ranging from 21- to 27-mm in diameter. A transfemoral JenaValve Plus is currently being developed with sim- 


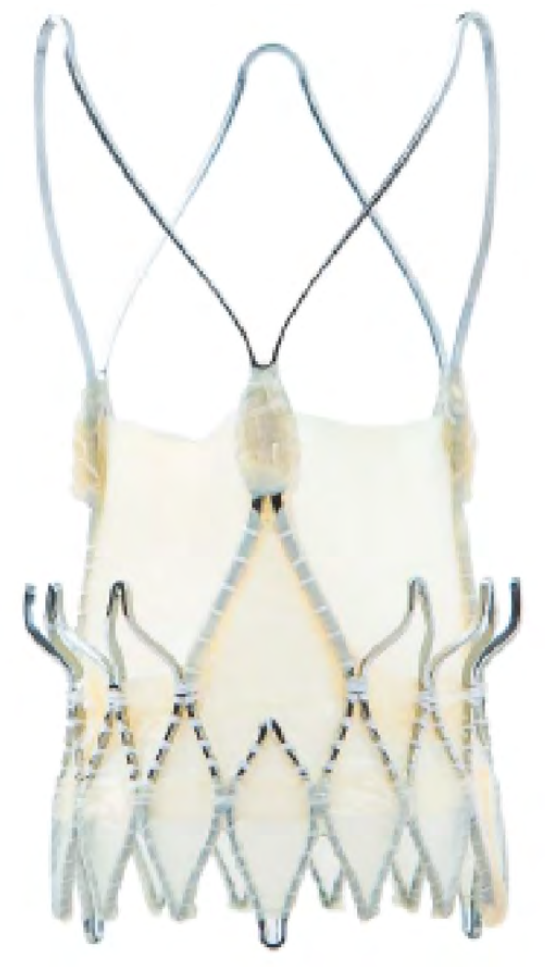

Figure 13: The ACURATE TA valve. A self-expandable valve composed of a nitinol stent frame and a biological tissue valve mounted within the stent. A polyethylene terephthalate skirt is mounted at the intra-annular part of the stent body.

ilar features and an $18 \mathrm{Fr}$ delivery system that is composed of three combined coaxial catheters [33].

A pivotal study for CE mark approval included transapical JenaValve implantations in 73 patients with severe AS [34]. Mean transaortic gradient was reduced post-procedurally from $40.6 \pm 15.9 \mathrm{~mm} \mathrm{Hg}$ to $10.0 \pm 7.2 \mathrm{~mm} \mathrm{Hg},(p<0.001)$, and AVA increased from $0.7 \pm 0.2 \mathrm{~cm}^{2}$ to $1.7 \pm 0.6 \mathrm{~cm}^{2}(p<0.001)$ and there was no or minimal PV-AR in $86.4 \%$ of the patients. Procedural success rate was $89.6 \%$, perioperative stroke occurred in two cases (3\%) and pacemaker implantation was necessary in six patients (9.1\%). Seiffert et al. have described a case series of five patients that underwent transapical implantation of a JenaValve for moderate to severe, non-calcified AR [32]. Implantation was successful in all cases without relevant remaining $A R$ or AS. No major device- or procedure-related adverse events occurred and all patients were alive with improved exercise tolerance at 3-month follow-up. JenaValve has a CE mark for treatment of patients with

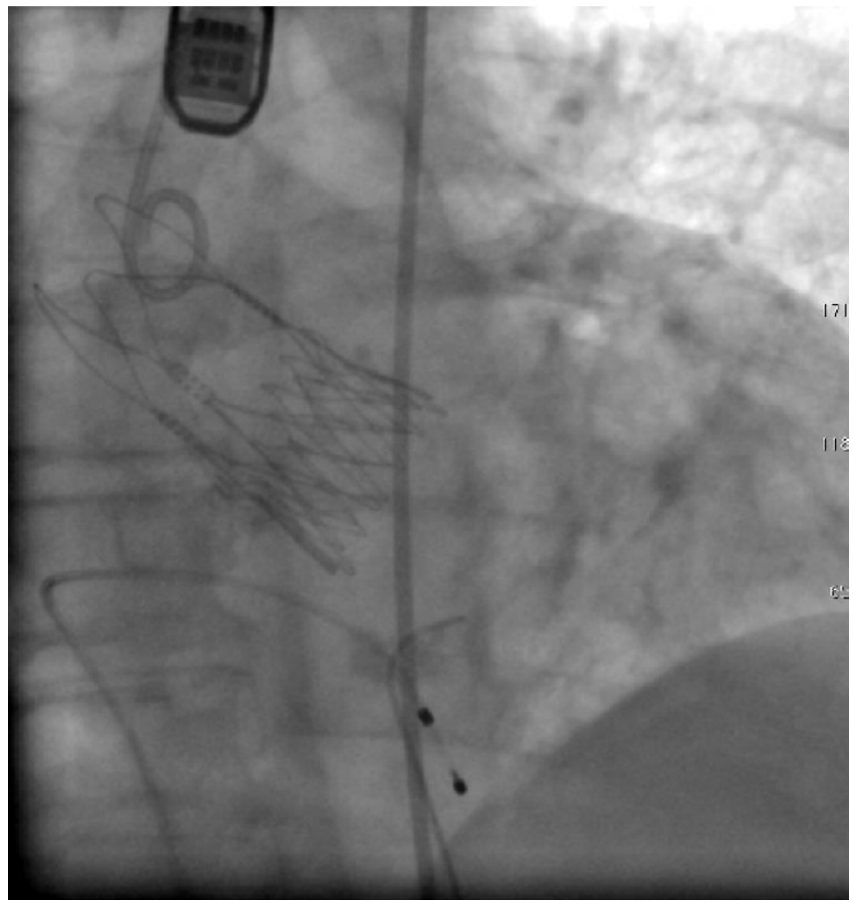

Figure 14: Angiography of an ACURATE TA valve.

AS since 2011 and for treatment of patients with noncalcified AR since 2013.

Currently ongoing trial with JenaValve is the JUPITER registry (long-term safety and performance of the JenaValve; ClinicalTrials.gov Identifier: NCT01598844).

\section{Symetis ACURATE TA / TF}

The self-expanding ACURATE TA device (Symetis SA, Ecublens, Switzerland) has been specifically developed for the transapical approach [35]. The nitinol stent frame was designed to facilitate a simple single-operator two-step implantation technique (Figures 13 and 14). Three arches are mounted at the distal edge of the stent body to stabilize the prosthesis during final deployment. The upper crown is formed by the most distal part of the stent body and is meant to embrace the native calcified leaflets. The stent commissures are well visible under fluoroscopy with a circular radiopaque appearance which facilitates anatomical rotation of the prosthesis for commissural alignment. A biological tissue valve is 
mounted within the nitinol stent. This valve has a similar leaflet thickness to conventional surgical porcine tissue valves because the design does not require excessive "crimping" of the leaflets. To minimize PV$A R$, a polyethylene terephthalate skirt is mounted at the proximal (intra-annular) part of the stent body. The delivery system is based on a sheathless concept similar in size to a $28 \mathrm{Fr}$ sheath system. Valve deployment is facilitated using a simple rotational knob suitable for a single-operator technique. Until final release the system allows for resheathing and repositioning. Three different sizes (labeled small, medium and large) are available allowing for treatment of patients presenting with an annulus diameter ranging from 20-27 mm. A transfemoral version of this device called ACURATE TF is very similar to the ACURATE TA device [36]. A $20 \mathrm{Fr}$ delivery system has a flexible shaft facilitating easy tracking even in tortuous aortic anatomy. It allows a controlled three-step implantation of the prosthesis. There is also a newer transfemoral version called ACURATE neo that has a 15 Fr compatible delivery system.

The results of a first-in-human trial in 40 patients that underwent ACURATE TA implantation including 6 month follow-up have been published [35, 37]. Device success rate was $92.5 \%$, mean transaortic gradient was reduced from $51.9 \pm 14.3 \mathrm{~mm} \mathrm{Hg}$ to 11.9 $\pm 5.8 \mathrm{~mm} \mathrm{Hg}$. Thirty-day mortality was $12.5 \%$ and major stroke rate was $5 \%$. At 6 months, only $3.3 \%$ of patients had more than mild PV-AR. Similar outcome have been published recently in a series of 62 patients [38]. A first-in-human trial in 20 patients treated with the ACURATE TF device has also been published [36]. The effective orifice area improved from $0.7 \mathrm{~cm}^{2}$ to $1.8 \mathrm{~cm}^{2}$ and only one patient had a grade 2 PV-AR. Procedural success rate was $95 \%$ with one case of stroke, and two pacemaker implantations at 30 days. ACURATE TA device has a CE mark obtained at 2011 and ACURATE neo device has a CE mark obtained at 2014.

\section{Medtronic Engager}

The Engager Aortic Valve bioprosthesis (Medtronic, Minneapolis, MN, USA) is a biological valve prosthesis composed of three leaflets cut from tissue-fixated bovine pericardium, sewn to a polyester sleeve and mounted on a compressible and self-expanding niti-

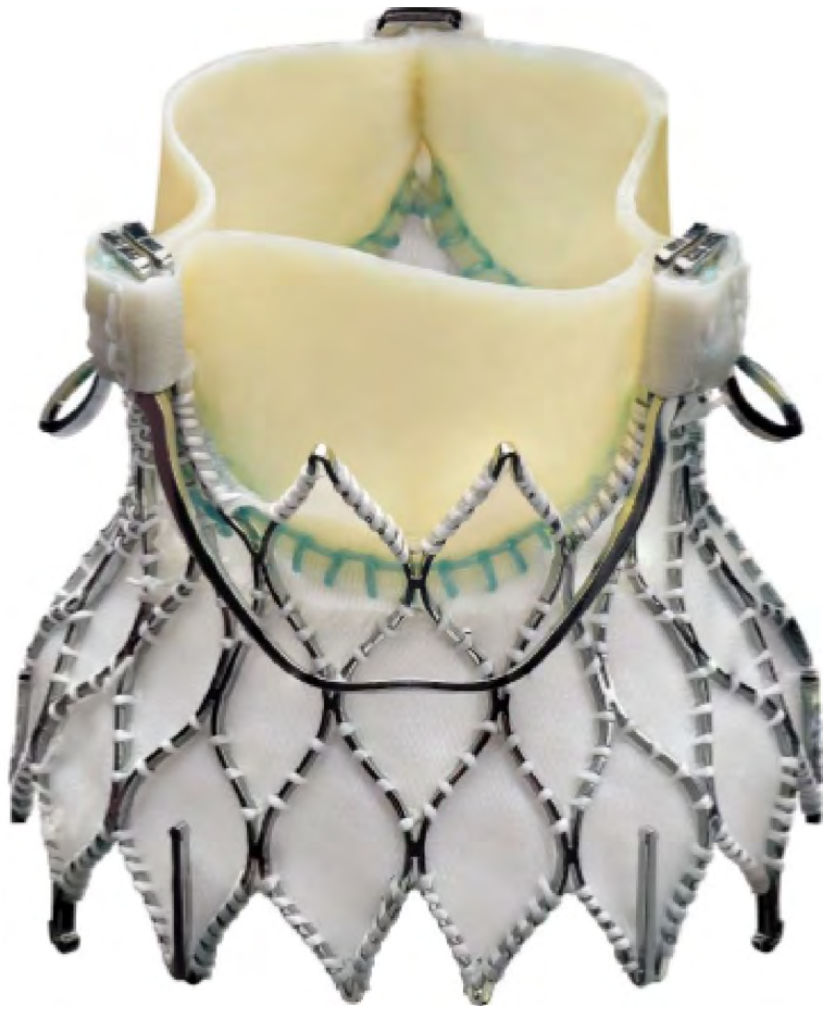

Figure 15: The Engager Aortic valve bioprosthesis. A selfexpandable valve composed of three leaflets cut from tissuefixated bovine pericardium, sewn to a polyester sleeve and mounted on a nitinol frame.

nol frame [39] (Figure 15). The stent assembly consists of a shaped main frame and a support frame, which are coupled together so as to form the commissural posts of the valve. Two types of sewing materials are used: polyester and expanded polytetrafluoroethylene. The valve design is intended to minimize PV-AR. The prosthesis is available in two sizes $(23 \mathrm{~mm}$ and $26 \mathrm{~mm}$ ) covering annulus diameters from 21 to $27 \mathrm{~mm}$ [40]. To achieve an anatomically correct position and to minimize the risk of coronary obstruction, the side arms fixed at the main frame of the prosthesis are designed to be placed into the sinuses of the aortic root. The valve can be repositioned before final deployment. Implantation is performed transapically with an over-the-wire delivery system comprising an introducer and a flexible delivery catheter which form one integral unit. The delivery system is composed of a $29 \mathrm{Fr}$ (inner diameter) introducer and a flexible delivery catheter with a $13 \mathrm{Fr}$ shaft. Engager valve has a CE mark for treatment of patients with AS since 2013. 


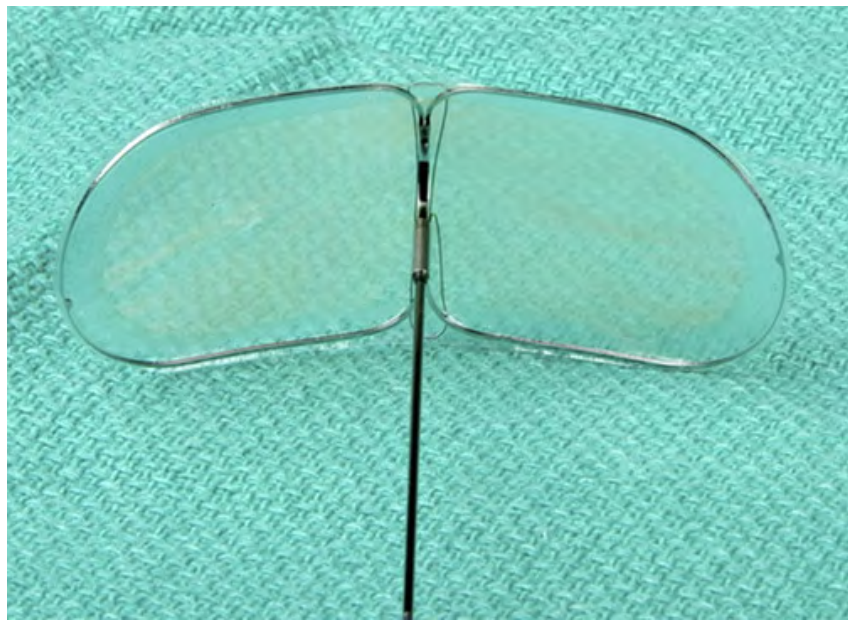

Figure 16: The Embrella Embolic Deflector system. The device consists of an oval-shaped nitinol frame covered with a porous polyurethane membrane that is positioned at the level of the aortic arch with the purpose of deflecting embolic debris generated during TAVR procedures.

A feasibility study with the Engager system was conducted in 10 patients [39]. All 10 patients were implanted successfully. There were no device related complications. At 30 days, one patient died from multi-organ failure. The mean aortic gradient post-procedurally was $15.6 \pm 4.9 \mathrm{~mm} \mathrm{Hg}$, and no more than a mild PV-AR was seen as assessed by echocardiography. The results of the first 61 patients enrolled in the European pivotal trial have showed all-cause mortality of $9.9 \%$ at 30 days, mean aortic valve gradient of $11.5 \pm 5.0 \mathrm{~mm} \mathrm{Hg}$, and no PV-AR greater than mild [41].

Two clinical trials evaluating efficacy and safety of the Medtronic Engager valve implantation are currently ongoing (ClinicalTrials.gov Identifier: NCT01348438, NCT01789567)

\section{The Helio Transcatheter Aortic Dock}

The Helio transcatheter aortic dock (Edwards Lifesciences, Irvine, CA, USA) is the first dedicated transcatheter device for the treatment of pure AR [42]. It consists of a self-expandable nitinol stent encased in polyethylene terephthalate fabric. The dock is fixed inside the aortic root and it is intended to assist in annular fixation of a standard balloon-expandable SAPIEN XT valve by incorporating and entrapping

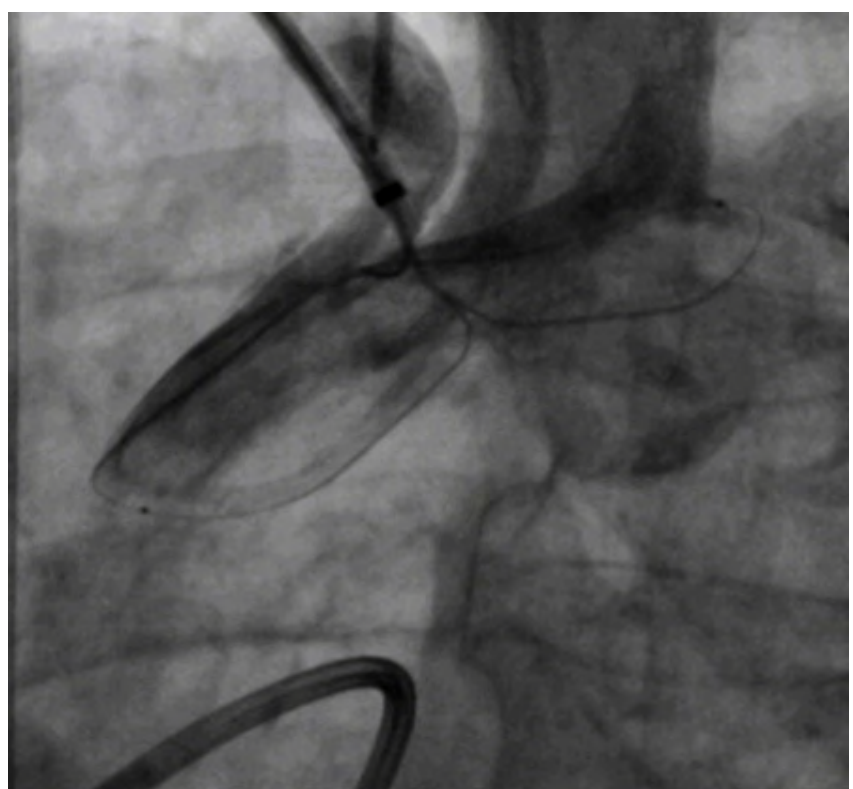

Figure 17: Angiographic image after deployment of the Embrella Embolic Deflector system at the level of the greater curvature of the aortic arch.

the native cusps. The currently available dock has a diameter of $25 \mathrm{~mm}$, suitable for implantation with a $29 \mathrm{~mm}$ SAPIEN XT valve. It is intended that future devices will be compatible with a full range of balloon-expandable valves. The Helio delivery catheter is advanced through the $16 \mathrm{Fr}$ eSheath over the stiff wire. The dock is then expanded within the aortic root by retracting a covering sleeve and positioned deep within the sinuses but outside the aortic valve cusps. A NovaFlex (Edwards Lifesciences, Irvine, CA, USA) delivery catheter is then advanced through the contralateral femoral sheath and a SAPIEN XT valve positioned within the dock and within the native valve. The clinical data currently available on this device is limited. In the first-in-human feasibility trial, four patients were treated successfully with a combined transfemoral-transapical approach. All of them were alive at 30 days and had no residual AR [43]. A fully percutaneous bilateral transfemoral approach is currently being evaluated.

\section{Cerebral Protection Devices}

Cerebrovascular events are among the most serious adverse events reported after TAVR and are associated with increased morbidity and mortality. The incidence of cerebrovascular events during the 30- 


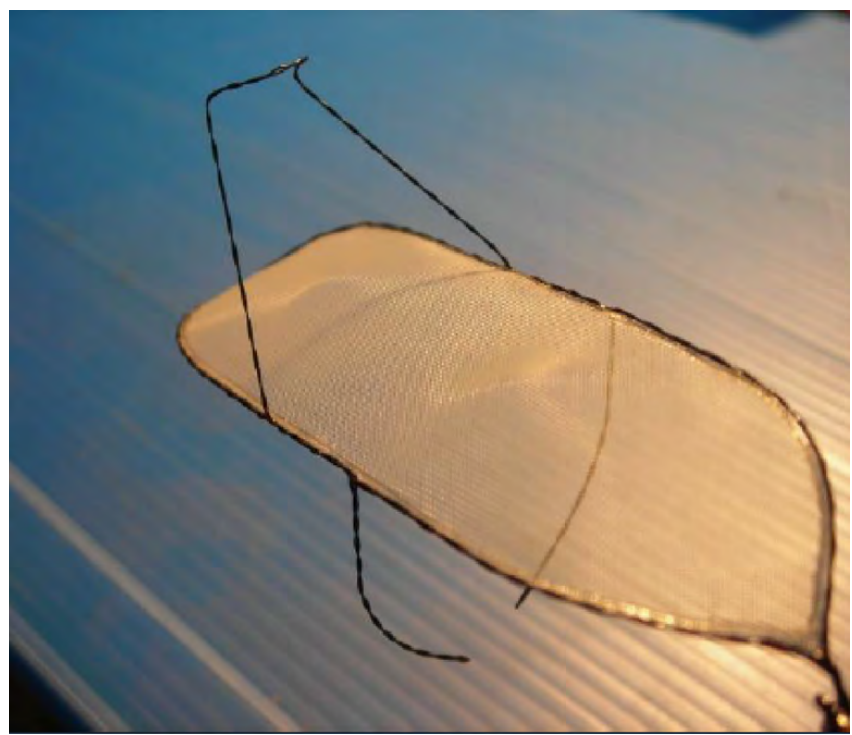

Figure 18: The TriGuard Cerebral Protection Device. The device consists of a nitinol mesh and a nitinol frame with two stabilizers that anchor the device in the brachiocephalic trunk and at the inner curvature of the aortic arch.

day period after TAVR ranges from $3 \%$ to $7 \%$, with the majority of patients experiencing 'major' strokes [11]. The observation that most cerebrovascular events occur within the first days after device implantation, implies that the stroke has a thromboembolic origin [44]. In order to minimize the risk of thromboembolic cerebrovascular accidents during TAVR, cerebral protection devices are currently being developed.

\section{Embrella Embolic Deflector}

The Embrella Embolic Deflector system (Edwards Lifesciences, Irvine, Ca, USA) consists of an oval-shaped nitinol frame covered with a porous polyurethane membrane that is positioned at the level of the aortic arch with the purpose of deflecting embolic debris generated during TAVR procedures [45] (Figures 16 and 17). The device is inserted via the right radial or brachial approach using a $6 \mathrm{Fr}$ delivery system. The frame of the device has two opposing petals that are positioned along the greater curvature of the aorta, covering the ostia of both the brachiocephalic and the left common carotid arteries. In a pilot study recently published, the Embrella Embolic Deflector system was used in 41 patients during TAVR, compared to 11 patients that underwent TAVR without embolic protection [45]. The system was successfully deployed at the level of the aortic arch

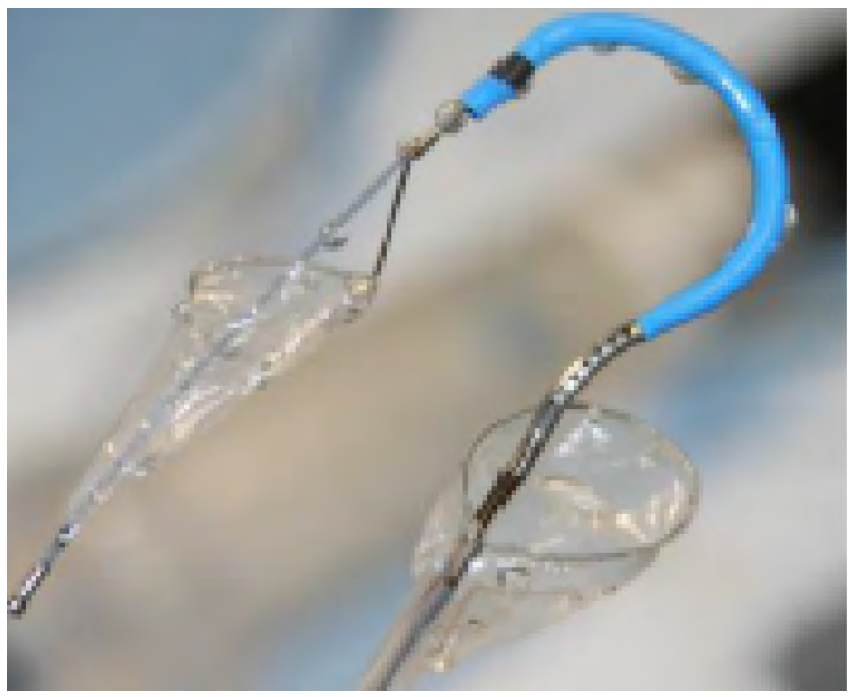

Figure 19: The Montage Dual Filter system. The conically shaped filters consist of a nitinol frame and polyurethane laser-drilled filter membrane with $140 \mu \mathrm{m}$-diameter pores. The filters are advanced to the brachiocephalic trunk and the left common carotid arteries before valve deployment.

in all patients with no complications. The use of the system was associated with a lower cerebral lesion volume demonstrated with diffusion weighted magnetic resonance imaging (DW-MRI) compared with the control group $(p=0.003)$.

\section{TriGuard}

The TriGuard Cerebral Protection Device (Keystone Heart Ltd, formerly SMT Research \& Development, Caesarea, Israel) is introduced via the femoral artery. The concept is similar to that of the Embrella device with some notable differences. A 9 Fr sheath is usually used for delivery and retrieval and allows additional placement of a pigtail catheter for procedural guidance. The device itself consists of a nitinol mesh and a nitinol frame with two stabilizers that anchor the device in the brachiocephalic trunk and at the inner curvature of the aortic arch [46] (Figure 18). Initial clinical experience in 15 patients demonstrated successful placement of the embolic protection device in all of them without procedural complications [47]. No patient developed new neurological symptoms except one patient who suffered from TIA two days after the procedure. DW-MRI showed 3.2 new cerebral lesions per patient, compared to 7.2 new lesions per patient in a historical control group without the device. The 


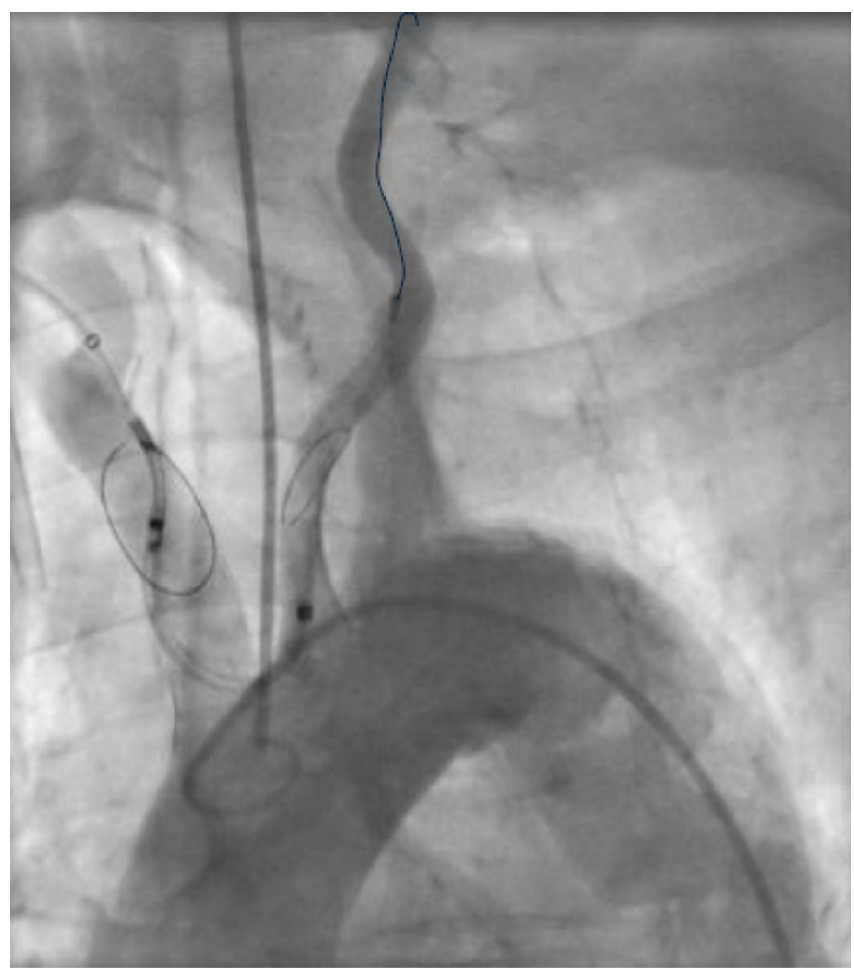

Figure 20: Angiographic image of the Montage Dual Filter System. The filters are located in the brachiocephalic trunk and the left common carotid arteries.

recently published DEFLECT III trial included 46 patients treated with TriGuard vs. 39 control patients [48]. TriGuard use was associated with greater freedom from new ischemic brain lesions ( 26.9 vs. $11.5 \%$ ), fewer new neurologic deficits detected by the $\mathrm{Na}$ tional Institutes of Health Stroke Scale (3.1 vs. 15.4\%) and better performance on a delayed memory task $(p=0.028)$.

\section{Claret CE Pro / Montage Dual Filter System}

The Montage Dual Filter System (Claret Medical Inc., Santa Rosa, CA, USA) is designed to capture embolic debris travelling to the brain in the brachiocephalic trunk and the left common carotid arteries [46]. The catheter is delivered through a $6 \mathrm{Fr}$ sheath via the radial or brachial artery. The conically shaped filters consist of a nitinol frame and polyurethane laser-drilled filter membrane with $140 \mu \mathrm{m}$-diameter pores (Figures 19 and 20). The filter frames are radiopaque and once deployed seal against the vessel wall, allowing filtered blood to pass to the brain while trapping debris. After positioning of the first filter in the bra- chiocephalic trunk, the catheter is advanced further in the aortic arch under fluoroscopic guidance and the tip of the delivery system is curved towards the left common carotid artery for placement of the second filter. The safe use of the system has been demonstrated in first-in-human study, which included 40 patients [49]. Technical success rate with delivery of the proximal and distal filter was $60 \%$ for the first generation device and $87 \%$ for the second-generation device. Captured debris was documented in at least 19 of 35 implanted devices (54.3\%). No procedural TIAs or strokes have occurred. Recently, the results of the CLEAN-TAVI trial were presented [50]. It is a prospective, double-blinded, randomized-controlled trial that included 100 patients. Cerebral protection device success was $96 \%$ (48/50). The number and volume of cerebral lesions as determined by DW-MRI subtraction was significantly reduced in the cerebral protection group. Two days post TAVR, neurological deficit was observed in $28 \%$ of patients in the control group compared to $13 \%$ of patients in the cerebral protection group $(p=0.08)$.

\section{Conclusions}

TAVR has emerged as an established technique for the treatment of patients with symptomatic severe AS. Cumulative evidence has proven the short- and midterm efficacy of this procedure, while improvements in implantation techniques and advances in TAVR technology have created high expectations for the future. The main challenges derived from the clinical experience with the first-generation TAVR devices were to reduce neurological and vascular complications and to minimize rates of PV-AR. The new-generation TAVR devices are currently in early clinical evaluation and have been specifically developed and designed to overcome these challenges. The features of these devices should allow the delivery catheter profile to be reduced, facilitate accurate positioning, repositioning and retrieval if needed, and reduce the incidence of significant PV-AR. New cerebral protection devices are expected to reduce clinical and sub-clinical embolic events. Although preliminary data with these new devices seem very promising, the clinical experience is still limited and more long-term data are required. 
Nevertheless, continuous effort to develop, improve and clinically evaluate these devices and techniques will eventually enable safe alternative to aortic valve surgery for an increasing number of patients. in Entourage Medical. Dr. Jilaihawi is a consultant for Edwards Lifesciences Corporation, St. Jude Medical, and Venus MedTech.

\section{Conflict of Interest}

Dr. Makkar is a consultant and has received grant support from Edwards Lifesciences Corporation, Medtronic Inc., and St. Jude Medical; and holds equity

\section{References}

1. Makkar RR, Fontana GP, Jilaihawi H, Kapadia S, Pichard AD, Douglas PS, et al. Transcatheter aortic-valve replacement for inoperable severe aortic stenosis. $\mathrm{N}$ Engl J Med. 2012;366:1696-1704. DOI: 10.1056/ NEJMoa1202277

2. Kodali SK, Williams MR, Smith CR, Svensson LG, Webb JG, Makkar RR, et al. Two-year outcomes after transcatheter or surgical aortic-valve replacement. $\mathrm{N}$ Engl J Med. 2012;366:1686-1695. DOI: 10.1056/NEJMoa1200384

3. Cribier A, Eltchaninoff $H$, Bash A, Borenstein N, Tron C, Bauer F, et al. Percutaneous transcatheter implantation of an aortic valve prosthesis for calcific aortic stenosis: First human case description. Circulation. 2002;106:3006-3008. DOI: 10.1161/01. CIR.0000047200.36165.B8

4. Adams DH, Popma JJ, Reardon MJ, Yakubov SJ, Coselli JS, Deeb GM, et al. Transcatheter aortic-valve replacement with a self-expanding prosthesis. N Engl J Med. 2014;370:1790-1798. DOI: 10.1056/NEJMoa 1400590

5. Thomas M, Schymik G, Walther T, Himbert $D$, Lefèvre $T$, Treede $H$, et al. Thirty-day results of the SAPIEN aortic Bioprosthesis European Outcome (SOURCE) Registry: A European registry of transcatheter aortic valve implantation using the Edwards SAPIEN valve. Circulation. 2010;122:62-69. DOI: 10.1161/CIRCULATIONAHA.109.907402

6. Gilard $M$, Eltchaninoff $H$, lung $B$, DonzeauGouge P, Chevreul K, Fajadet J, et al. Registry of transcatheter aortic-valve implantation in high-risk patients. N Engl J Med. 2012;366:1705-1715. DOI: 10.1056/NEJMoa1114705

7. Tamburino C, Capodanno D, Ramondo A, Petronio AS, Ettori F, Santoro G, et al. Incidence and predictors of early and late mortality after transcatheter aortic valve implantation in 663 patients with severe aortic stenosis. Circulation. 2011;123:299308. DOI: $10.1161 /$ CIRCULATIONAHA. 110.946533

8. Lerakis S, Hayek SS, Douglas PS. Paravalvular aortic leak after transcatheter aortic valve replacement: current knowledge. Circulation. 2013;127:397-407. DOI: 10.1161/CIRCULATIONAHA.112.142000

9. Généreux $P$, Head SJ, Hahn R, Daneault $B$, Kodali S, Williams MR, et al. Paravalvular leak after transcatheter aortic valve replacement: the new Achilles' heel? A comprehensive review of the literature. J Am Coll Cardiol. 2013;61:1125-1136. DOI: 10.1016/j.jacc.2012.08.1039

10. Moat NE, Ludman $P$, de Belder MA, Bridgewater $B$, Cunningham $A D$, Young $C P$, et al. Long-term outcomes after transcatheter aortic valve implantation in high-risk patients with severe aortic stenosis: the U.K. TAVI (United Kingdom Transcatheter Aortic Valve Implantation) Registry. J Am Coll Cardiol. 2011;58:2130-2138. DOI: 10.1016/j. jacc.2011.08.050

11. Fassa A-A, Himbert D, Vahanian A. Mechanisms and management of TAVR-related complications. Nat Rev Cardiol. 2013;10: 685-695. DOI: 10.1038/nrcardio.2013.156

12. Binder RK, Rodés-Cabau J, Wood DA, Webb JG. Edwards SAPIEN 3 valve. Eurolntervention. 2012;8(Suppl. Q):Q83-87. DOI: 10.4244/EIJV8SQA15

13. Binder RK, Rodés-Cabau J, Wood DA, Mok $M$, Leipsic J, De Larochellière $R$, et al. Transcatheter aortic valve replacement with the SAPIEN 3: a new balloonexpandable transcatheter heart valve. JACC Cardiovasc Interv. 2013;6:293-300. DOI: 10.1016/j.jcin.2012.09.019

14. Webb J, Gerosa G, Lefèvre T, Leipsic J, Spence $M$, Thomas $M$, et al. Multicenter evaluation of a next-generation balloon-expandable transcatheter aortic valve. J Am Coll
Cardiol. 2014;64:2235-2243. DOI: 10.1016/j. jacc.2014.09.026

15. Kodali S. Clinical and echocardiographic outcomes at 30 days with the SAPIEN 3 TAVR system in inoperable, high-risk and intermediate-risk AS patients. Presented at ACC 2015.

16. Sinning J-M, Werner N, Nickenig G, Grube E. Medtronic CoreValve Evolut valve. Eurolntervention. 2012;8(Suppl. Q):Q94-96. DOI: 10.4244/EIJV8SQA17

17. Fairley SL, Jeganathan R, Manoharan G, Spence MS. Early experience of implantation of the new CoreValve( $\left.{ }^{\circledR}\right)$ Evolut(TM) in degenerated bioprosthetic aortic valves. Catheter Cardiovasc Interv. 2014;83:485492. DOI: $10.1002 / \mathrm{ccd} .25125$

18. Zavalloni D, De Benedictis M, Pagnotta P, Scrocca I, Presbitero P. New CoreValve Evolut $23 \mathrm{~mm}$ technology for treatment of degenerated bioprosthesis. Heart Lung Circ. 2014;23:183-185. DOI: 10.1016/j. hlc.2013.08.002

19. Piazza N, Martucci G, Lachapelle K, de Varennes B, Bilodeau L, Buithieu J, et al. First-in-human experience with the Medtronic CoreValve Evolut R. Eurolntervention. 2014;9:1260-1263. DOI: 10.4244/ EIJV9I11A215

20. Meredith IT. 6-month outcomes following transcatheter aortic valve implantation with a novel repositionable self-expanding bioprosthesis. Presented at EuroPCR 2015.

21. Meredith IT, Hood KL, Haratani N, Allocco DJ, Dawkins KD. Boston Scientific Lotus valve. Eurolntervention. 2012;8(Suppl. Q):Q70-74. DOI: 10.4244/EIJV8SQA12

22. Meredith Am IT, Walters DL, Dumonteil N, Worthley SG, Tchétché $D$, Manoharan G, et al. Transcatheter aortic valve replacement for severe symptomatic aortic stenosis using a repositionable valve system: $30-$ day primary endpoint results from the RE- 
PRISE II study. J Am Coll Cardiol. 2014;64: 1339-1348. DOI: 10.1016/j.jacc.2014.05.067

23. Bijuklic K, Tübler T, Low RI, Grube E, Schofer J. Direct Flow Medical valve. Eurolntervention. 2012;8(Suppl. Q):Q75-78. DOI: 10.4244/EIJV8SQA13

24. Schofer J, Colombo A, Klugmann S, Fajadet $J$, DeMarco $F$, Tchétché $D$, et al. Prospective multicenter evaluation of the direct flow medical transcatheter aortic valve. J Am Coll Cardiol. 2014;63:763-768. DOI: 10.1016/j.jacc.2013.10.013

25. Manoharan G, Spence MS, Rodés-Cabau J, Webb JG. St Jude Medical Portico valve. Eurolntervention. 2012;8(Suppl. Q):Q97-101. DOI: 10.4244/EIJV8SQA18

26. Willson $A B$, Rodès-Cabau J, Wood DA, Leipsic J, Cheung A, Toggweiler $S$, et al. Transcatheter aortic valve replacement with the St. Jude Medical Portico valve: first-in-human experience. J Am Coll Cardiol. 2012;60:581-586. DOI: 10.1016/j. jacc.2012.02.045

27. Urena M, Doyle D, Rodés-Cabau J, Dumont E. Initial experience of transcatheter aortic valve replacement with the St Jude Medical Portico valve inserted through the transapical approach. J Thorac Cardiovasc Surg. 2013;146:e24-27. DOI: 10.1016/j. jtcvs.2013.06.005

28. Ribeiro HB, Urena M, Kuck K-H, Webb JG, Rodés-Cabau J. Edwards CENTERA valve. Eurolntervention. 2012;8(Suppl. Q):Q7982. DOI: 10.4244/EIJV8SQA14

29. Binder RK, Schäfer U, Kuck K-H, Wood DA, Moss R, Leipsic J, et al. Transcatheter aortic valve replacement with a new self-expanding transcatheter heart valve and motorized delivery system. JACC Cardiovasc Interv. 2013;6:301-307. DOI: 10.1016/j. jcin.2013.01.129

30. Sievert H. The Venus A TAVR system. Presented at TVT 2015.

31. Treede $H$, Rastan $A$, Ferrari $M$, Ensminger $S$, Figulla H-R, Mohr F-W. JenaValve. Eurolntervention. 2012;8(Suppl. Q):Q88-93. DOI: 10.4244/EIJV8SQA16

32. Seiffert $M$, Diemert $P$, Koschyk $D$, Schirmer J, Conradi L, Schnabel R, et al. Transapical implantation of a second-generation transcatheter heart valve in patients with noncalcified aortic regurgitation. JACC Cardiovasc. Interv. 2013;6:590-597. DOI: 10.1016/j.jcin.2013.01

33. Rudolph TK, Baldus S. JenaValveTransfemoral technology. Eurolntervention. 2013;9(Suppl.):S101-102. DOI: 10.4244/EIJV9SSA20

34. Treede H, Mohr F-W, Baldus S, Rastan A, Ensminger $S$, Arnold M, et al. Transapical tran- scatheter aortic valve implantation using the JenaValveTM system: Acute and 30-day results of the multicentre CE-mark study. Eur J Cardio-Thorac Surg. 2012;41:e131138. DOI: $10.1093 /$ ejcts/ezs129

35. Kempfert J, Möllmann H, Walther T. Symetis ACURATE TA valve. Eurolntervention. 2012;8(Suppl. Q):Q102-109. DOI: 10.4244/ EIJV8SQA19

36. Möllmann $H$, Diemert $P$, Grube $E$, Baldus S, Kempfert J, Abizaid A. Symetis ACURATE TFTM aortic bioprosthesis. Eurolntervention. 2013;9(Suppl.):S107-110. DOI: 10.4244/EIJV9SSA22

37. Kempfert J, Treede H, Rastan AJ, Schönburg M, Thielmann M, Sorg S, et al. Transapical aortic valve implantation using a new self-expandable bioprosthesis (ACURATE TATM): 6-month outcomes. Eur J Cardio-Thorac Surg. 2013;43:52-56, 57. DOI: 10.1093/ejcts/ezs139

38. Seiffert M, Conradi L, Kloth B, Koschyk D, Schirmer J, Schnabel RB, et al. Singlecentre experience with next-generation devices for transapical aortic valve implantation. Eur J Cardio-Thorac Surg. 2014. DOI: 10.1093/ejcts/ezu041

39. Sündermann SH, Grünenfelder J, Corti R, Rastan AJ, Linke A, Lange R, et al. Feasibility of the EngagerTM aortic transcatheter valve system using a flexible over-thewire design. Eur. J. Cardio-Thorac. Surg. 2012;42:e48-52. DOI: 10.1093/ejcts/ezs389

40. Sündermann SH, Holzhey D, Bleiziffer S, Treede H, Falk V. Medtronic EngagerTM bioprosthesis for transapical transcatheter aortic valve implantation. Eurolntervention. 2013;9(Suppl.):S97-100. DOI: 10.4244/EIJV9SSA19

41. Holzhey $D$, Linke A, Treede $H$, Baldus $S$, Bleiziffer $S$, Wagner A, et al. Intermediate follow-up results from the multicenter engager European pivotal trial. Ann Thorac Surg. 2013;96:2095-2100. DOI: 10.1016/j. athoracsur.2013.06.089

42. Barbanti M, Ye J, Pasupati S, El-Gamel A, Webb JG. The Helio transcatheter aortic dock for patients with aortic regurgitation. Eurolntervention. 2013;9(Suppl.):S91-94. DOI: 10.4244/EIJV9SSA17

43. Pasupati S. A novel approach to aortic insufficiency: Edwards Helio System-Feasibility trial. Presented at EuroPCR 2013.

44. Stortecky S, Windecker S, Pilgrim T, Heg D, Buellesfeld $L$, Khattab AA, et al. Cerebrovascular accidents complicating transcatheter aortic valve implantation: frequency, timing and impact on outcomes. Eurolntervention. 2012;8:62-70. DOI: 10.4244/ EIJV8I1A11
45. Rodés-Cabau J, Kahlert $P$, Neumann F-J, Schymik G, Webb JG, Amarenco P, et al. Feasibility and exploratory efficacy evaluation of the umbrella embolic deflector system for the prevention of cerebral emboli in patients undergoing transcatheter aortic valve replacement: The PROTAVI-C Pilot Study. JACC CardiovasC Interv. 2014;7:1146-1155. DOI: 10.1016/j. jcin.2014.04.019

46. Praz F, Nietlispach F. Cerebral protection devices for transcatheter aortic valve implantation: is better the enemy of good? Eurolntervention. 2013;9(Suppl.):S124-128. DOI: 10.4244/EIJV9SSA26

47. Onsea K, Agostoni P, Samim M, Voskuil M, Kluin J, Budde R, et al. First-in-man experience with a new embolic deflection device in transcatheter aortic valve interventions. Eurolntervention. 2012;8:51-56. DOI: 10.4244/EIJV8I1A9

48. Lansky AJ, Schofer J, Tchetche D, Stella P, Pietras CG, Parise $\mathrm{H}$, et al. A prospective randomized evaluation of the TriGuardTM $\mathrm{HDH}$ embolic DEFLECTion device during transcatheter aortic valve implantation: results from the DEFLECT III trial. Eur Heart J. 2015 May 19. [Epub ahead of print]. DOI:10.1093/eurheartj/ehv191

49. Naber CK, Ghanem A, Abizaid AA, Wolf A, Sinning J-M, Werner $N$, et al. First-in-man use of a novel embolic protection device for patients undergoing transcatheter aortic valve implantation. Eurolntervention. 2012;8:43-50. DOI: 10.4244/EIJV8I1A8

50. Linke A. CLEAN-TAVI: A prospective, randomized trial of cerebral embolic protection in high-risk patients with aortic stenosis undergoing transcatheter aortic valve replacement. Presented at TCT 2014.

Cite this article as: Abramowitz $Y$, Chakravarty T, Jilaihawi H. Makkar RR. Update on new devices for transcatheter aortic valve replacement. Structural Heart Disease 2015;1(3):112-126. DOI: $\quad$ http://dx.doi.org/10.12945/j. jshd.2015.019-14 